\title{
Results of Studies of Fuel Efficiency of Diesel Engine When Operating on Multi-Component Fuel
}

\author{
Storozhev I.I. \\ State agrarian University of the Northern Trans-Urals \\ Tyumen, Russia \\ e-mail: sii-81.20.10@yandex.ru
}

\author{
Startcev A.V. \\ South Ural state agrarian University \\ Chelyabinsk, Russia \\ e-mail: sav.63.10.04@mail.ru
}

\begin{abstract}
The article presents the results of bench tests of the diesel engine D-240. To increase the power of the engine, the authors propose using humidification. The optimal cyclic water delivery equal to $17.452 \pm 0.87 \mathrm{mg} / \mathrm{cycle}$ was obtained. The authors have achieved: an increase in the effective power of the engine $D$ 240 by $10-12 \mathrm{~kW}(11-19 \%)$, reduction of specific effective fuel consumption from $245 \mathrm{~g} / \mathrm{kWh}$ to $208 \mathrm{~g} / \mathrm{kWh}$ (by $15 \%$ ). In addition, there has been increase in the effective power of the engine D-240 by $10-12 \mathrm{~kW}(11-19 \%)$, a reduction in specific effective fuel consumption from $245 \mathrm{~g} / \mathrm{kWh}$ to $208 \mathrm{~g} / \mathrm{kWh}$ (by 15 $\%)$. It has been found that the water delivery helps to reduce the toxicity of exhaust gases.
\end{abstract}

Keywords- fuel-water mixture, effective power, multicomponent fuel, ecology, thermodynamics.

\section{INTRODUCTION}

Modern industry and agriculture are impossible to imagine without an internal combustion engine. Today, the internal combustion engine is the main source of energy for mobile technological machines. According to statistics, in July 2016, the Russian Federation operated about 49.11 million transport vehicles [1]. If each transport vehicle will save at least one gram of fuel, it becomes easy to calculate that the overall economy of the country can be about 50 tons of fuel. It is obvious that our atmosphere will become cleaner for the same amount of combustion products. Therefore, the increase in fuel efficiency of machines, which use the diesel internal combustion engine as an energy unit, is the most important task of the national economy.

The purpose of this article is to assess the impact of humidification of fresh air by injecting water into the intake manifold or exhaust gas recirculation system of the diesel engine D-240 (tractor MTZ-80/82) on its fuel efficiency and ecological parameters. As a result, it has been found that the presence of water in the fresh air leads to significant savings in hydrocarbon fuel and improved ecological parameters of the diesel internal combustion engine.

\section{METHODS AND MATERIALS}

Experimental studies were carried out in the testing laboratory of the Federal state Agrarian University of the Northern Trans-Urals (Tyumen). The purpose of the tests was to check the basic theoretical provisions that reveal the impact of multi-component fuel on the increase in the effective power of the engine, to improve its fuel efficiency and environmental safety. In addition, the missing source data for the construction of a mathematical model were obtained. The technique of bench experimental studies was based on the technique set out in GOST 18509-88 "Tractor and combine diesels. Methods of bench tests". Thus, the recommendations were taken into account $[2,3]$.

Experimental studies of the fuel efficiency of the tractor diesel D-240 operating on the multicomponent fuel (fuel-water mixture) were carried out in three main stages. In order to improve the quality of the information obtained, the experiments were carried out with a three-, five-fold repetition, depending on the convergence of the results of the experiments. The maximum discrepancy between the results of one experiment was established within $\pm 5 \%$ [4-6]. The information obtained was processed by known methods of probability theory and mathematical statistics using the Microsoft Excel software package.

\section{RESULTS}

At the first stage, the diesel engine D-240 was tested in order to find the optimal composition of the mixture (characteristic of the composition of the working mixture). The maximum effective engine power (controlled factor - cyclic water delivery) was chosen as the optimization criterion. During the research, the water delivery was carried out in two ways:

- into the intake manifold of the engine with a calibrated injection jet;

- in the EGR (exhaust gas recirculation) system.

Water delivery was carried out by means of a specially designed device made on the basis of the carburetor of the starting engine K-61.

Figure 1 shows a fragment of processing the results of the research. The water delivery was carried out in the intake manifold of the engine D-240 by means of the injector with a calibrated nozzle. 
$\mathrm{Ne}, \quad \mathrm{kW}$

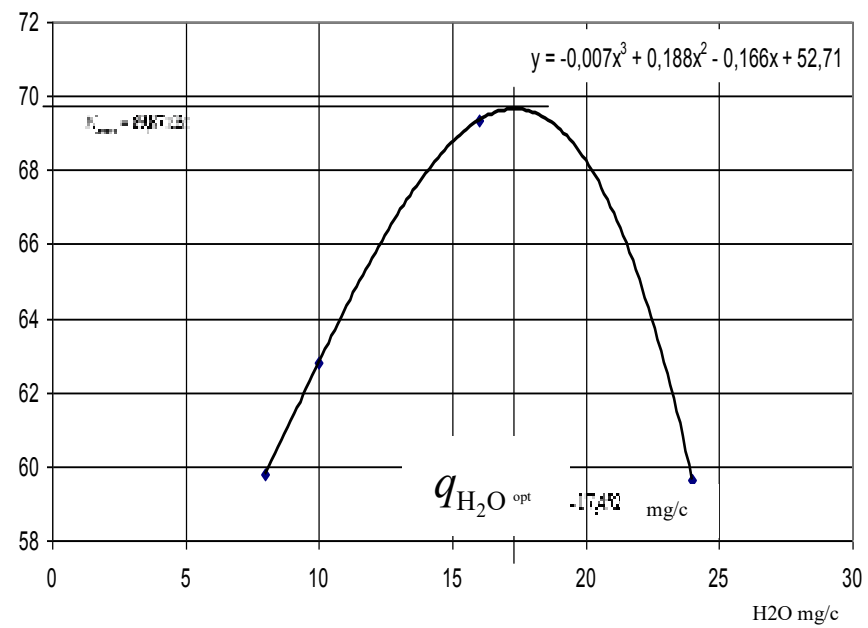

Fig. 1. Dependence of the effective power of the diesel engine D-240 on the rate of the cyclic flow of water (if water is injected into the intake manifold)

Regression analysis of the obtained experimental data showed that, within the limits of the factor space, the dependence of the effective power in the function cyclic water delivery with a sufficiently high degree of confidence $(\mathrm{R} 2=$ 0.99 ) can be expressed by a polynomial trend of the third order:

$$
\begin{gathered}
N_{e}=52,71-0,166 \cdot q_{\mathrm{H}_{2} \mathrm{O}}+0,188 \cdot q_{\mathrm{H}_{2} \mathrm{O}}^{2}-0,007 \cdot \\
q_{\mathrm{H}_{2} \mathrm{O}}^{3}, k W
\end{gathered}
$$

where $q_{\mathrm{H}_{2} \mathrm{O}}-$ the cyclic water delivery, $\mathrm{mg} /$ cycle.

After studying the expression (1) for the extremum, the optimal value $q_{\mathrm{H}_{2} \mathrm{O}}$ was determined:

$$
q_{\mathrm{H}_{2} \mathrm{O} \text { opt }} \quad{ }_{\mathrm{IT}}=17,452 \mathrm{mg} / \mathrm{c}
$$

The effective power of the engine D-240 at the same time was:

$$
N_{\text {e } \max }=69,87 \mathrm{~kW}
$$

By setting a $5 \%$ tolerance on the obtained value $q_{\mathrm{H}_{2} \mathrm{O}}$, the boundaries of the optimal values of the cyclic water delivery were determined:

$$
\begin{aligned}
& q_{\mathrm{H}_{2} \mathrm{O} \text { opt }}=17,452 \pm 0,87 \mathrm{mg} / \mathrm{c}, \\
& N_{\text {e } \max }=69,87 \pm 3,49 \mathrm{~kW}
\end{aligned}
$$

At nominal mode of operation of the engine D-240, the cyclic delivery of diesel fuel was $54 \mathrm{mg} /$ cycle. Respectively, the percentage of water in relation to diesel fuel was about 32 $\%$, which is in good agreement with the results of previous theoretical studies [7, 8].
Thus, as a result of experimental studies we have found that by injecting water into the intake manifold of the diesel engine D-240, its effective power can be increased by $10 \ldots 12 \mathrm{~kW}$ $(11 \ldots 19 \%)$ and reach almost $70 \mathrm{~kW}$ with the standard power of the engine of $59 \mathrm{~kW}$. Optimal cyclic water delivery at nominal mode of operation of the engine should be $17.452 \pm 0.87$ $\mathrm{mg} /$ cycle.

Figure 2 shows a fragment of processing the results of bench tests of the d-240 engine, when water is injected into the exhaust gas recirculation (EGR) system.

The analysis of the results showed that the dependence of the effective power of the engine D-240 on the value of the cyclic water delivery, supplied to the exhaust gas recirculation system, can be expressed by a polynomial trend of the second order (the degree of confidence is $\mathrm{R}^{2}=0.98$ ):

$$
N_{e}=46,46+0,8515 \cdot q_{\mathrm{H}_{2} \mathrm{O}}-0,0337 \cdot q_{\mathrm{H}_{2} \mathrm{O}}^{2}, \mathrm{~kW}
$$

Further analysis of figure 2 shows, when water is injected into the exhaust gas recirculation system that the reverse effect is observed. The presence of water reduces the effective power. The resulting negative effect can be explained by the fact that water vaporization occurs already in the intake manifold of the engine, due to the high temperature of the exhaust gases. The temperature of the exhaust gases of the engine at the nominal mode is within $500 \ldots 600^{\circ} \mathrm{C}$. As a result, the early vaporization of water in the intake manifold of the engine does not improve the filling of the cylinder and, as a result, does not lead to an increase in the indicator pressure during the combustion of diesel fuel.

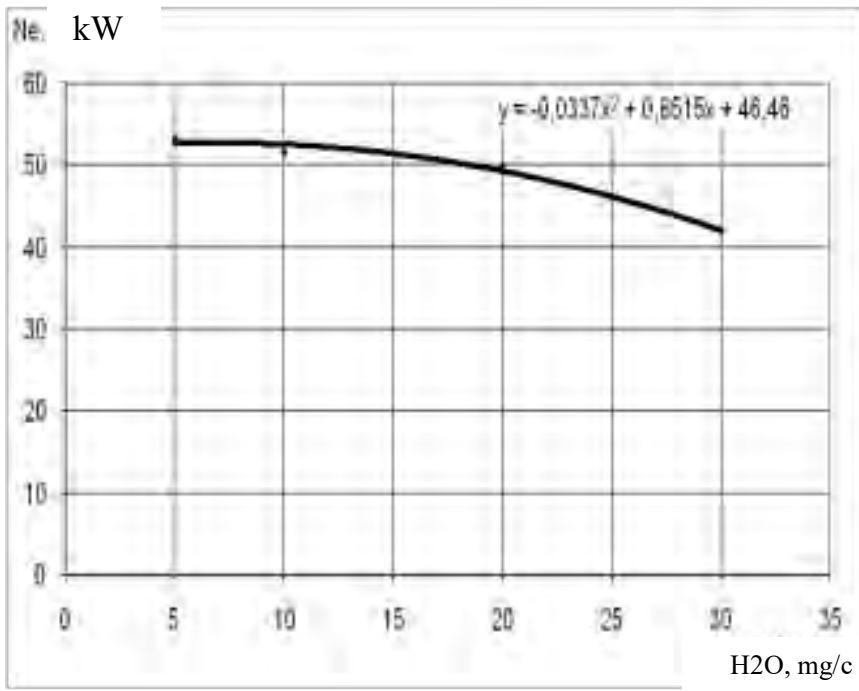

Fig. 2. Dependence of the effective power of the diesel engine D-240 on the rate of the cyclic flow of water (if water is injected into the EGR system)

Based on the above, we can conclude that we are able to get the increase in the effective power of the diesel engine D-240 by moistening the fresh air only in the case of injection of water into the intake manifold of the engine. The percentage of water should be about $30 . . .33 \%$ relative to diesel fuel. 
At the second stage of the research, the fuel efficiency of the D-240 engine was estimated by removing the external speed characteristic when the engine is operated with the regulator. At this stage of bench tests, the water delivery was carried out only in the intake manifold of the tested diesel and corresponded to the optimal cyclic water delivery $-32 \%$, taking into account the error not exceeding $\pm 5 \%$. 3.

The results of this stage of the research are shown in figure

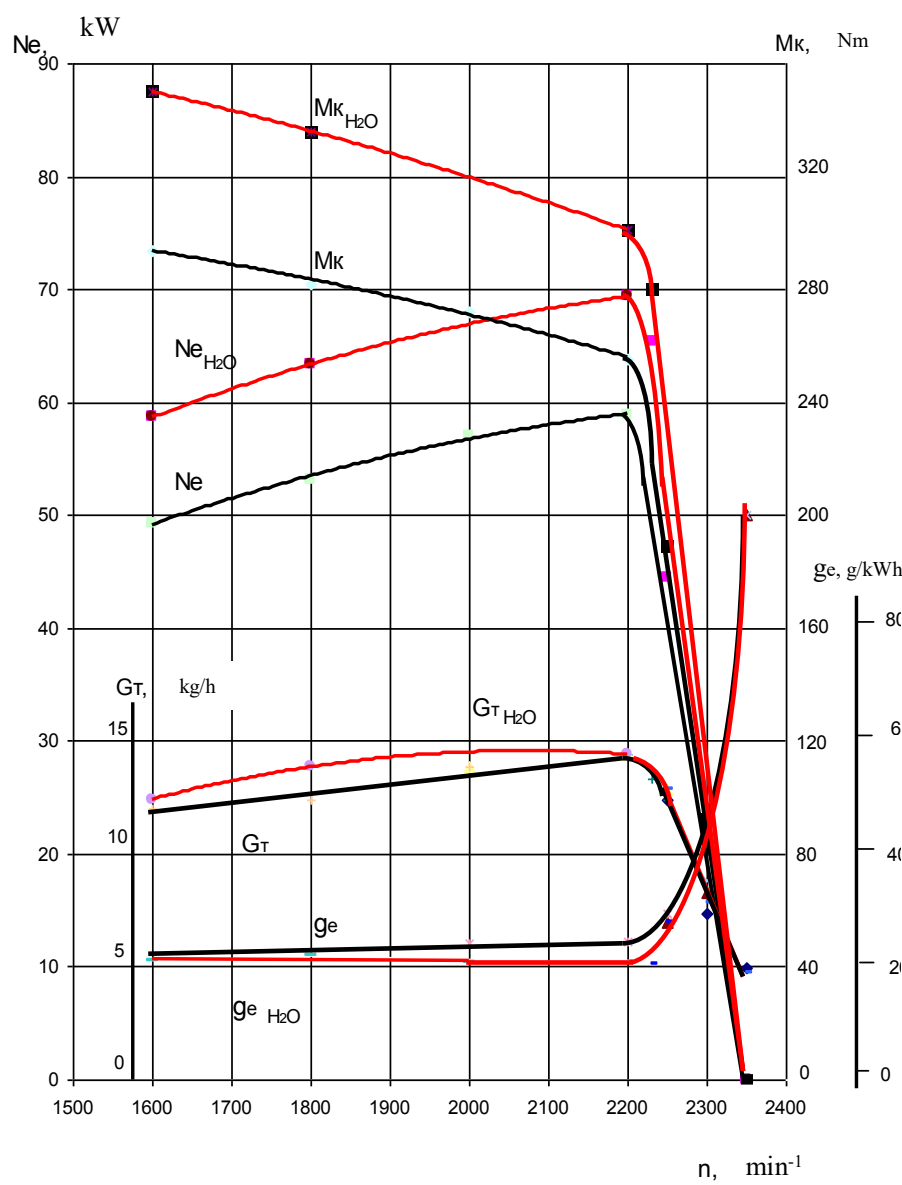

Fig. 3. Combined external speed characteristic of D-240 diesel when working with the regulator

Analysis of the speed characteristics of the diesel engine D240 , shown in figure 3 , shows that when moistening the fresh air in the intake manifold, the effective performance of the engine increases. In particular, the nominal operating mode of the experimental engine D-240 recorded an increase in the effective power, reaching $17 \ldots 19 \%$ (increase of $10 \ldots 12 \mathrm{~kW}$ ) with a corresponding increase in the effective torque from $254 \ldots 258 \mathrm{Nm}$ to $298 \ldots 306 \mathrm{Nm}(17 \ldots 19 \%)$, a decrease in the specific effective fuel consumption from $240 \ldots 250 \mathrm{~g} / \mathrm{kWh}$ to $210 \ldots .220 \mathrm{~g} / \mathrm{kWh}(12 \ldots 15 \%)$.

At the third and final stage of the research, the impact of water injection on the ecologic parameters of the engine was evaluated. The results of the research are presented in figures 4 , 5 .

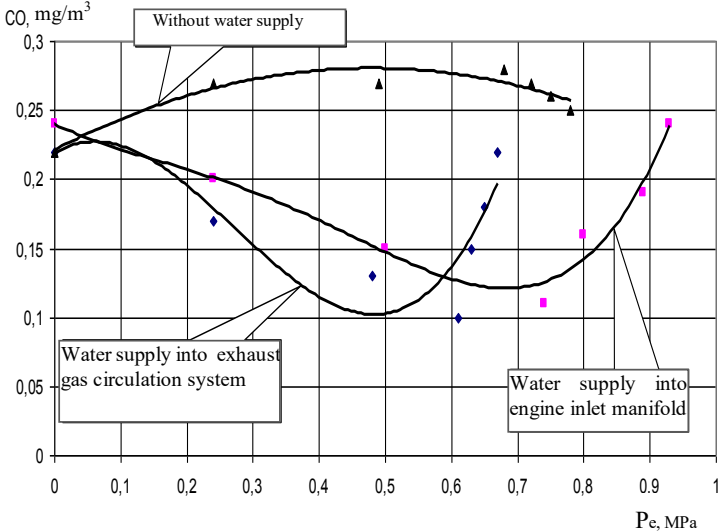

Fig. 4. CO content in the exhaust gases depending on the average effective pressure (Diesel engine D-240)

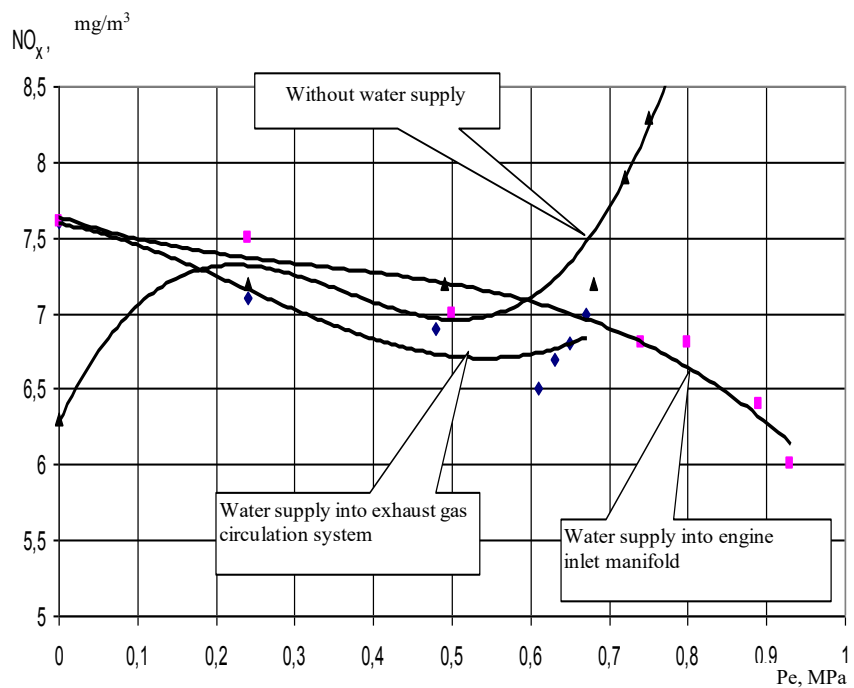

Fig. 5. NOx content in the exhaust gases depending on the average effective pressure (Diesel engine D-240)

As the main performance indicators of toxicity of exhaust gases of the engine, on the basis of analysis of literary sources $[9,10,11,12]$, was used:

- CO content, $\mathrm{mg} / \mathrm{m}^{3}$;

- NOx content, $\mathrm{mg} / \mathrm{m}^{3}$;

- smokiness, $\%$.

As a regulatory framework for the assessment of ecologic parameters of the engine, the requirements of Evro were used, the normative values of which are presented in the table. 
TABLE 1. EURO REQUIREMENTS FOR ENVIRONMENTAL PERFORMANCE OF AUTOMOTIVE ENGINES

\begin{tabular}{|l|l|c|c|c|c|}
\hline \multirow{2}{*}{} & \multirow{2}{*}{$\begin{array}{c}\text { Year of } \\
\text { introduction }\end{array}$} & \multicolumn{4}{|c|}{$\begin{array}{c}\text { The content of harmful substances in the } \\
\text { exhaust gases of the engine, mg/m3 }\end{array}$} \\
\cline { 3 - 6 } & & NOx & CO & CH & Solids particle \\
\hline Evro 3 & 2000 & 5,00 & 2,00 & 0,60 & 0,10 \\
\hline Evro 4 & 2005 & 3,50 & 1,80 & 0,50 & 0,09 \\
\hline Evro 5 & 2009 & 2,00 & 1,50 & 0,25 & 0,02 \\
\hline Evro 6 & 2015 & 0,40 & 1,50 & 0,13 & 0,01 \\
\hline
\end{tabular}

Analysis of the data showed that the humidification of the fresh charge as a whole leads to a decrease in the content of harmful substances in the exhaust gases of the diesel engine. Both methods are quite effective in reducing the toxicity of exhaust gases. The greatest efficiency was observed in reducing the content of carbon monoxide (CO). Here, the reduction can be achieved by $40 \ldots 60 \%$. The oxides of nitrogen $\left(\mathrm{NO}_{\mathrm{x}}\right)$ show a fairly contradictory situation. In particular, when idle, the use of water injection even contributes to an increase in $\mathrm{NO}_{\mathrm{x}}$, but with increasing load the situation changes and the $\mathrm{NO}_{\mathrm{x}}$ content decreases. This fact can be explained by different exhaust gas temperatures. In particular, when idle, the exhaust gas temperature is low enough, and water injection also contributes to its reduction, so the $\mathrm{NO}_{\mathrm{x}}$ content increases. As the load increases, the exhaust gas temperature increases and the $\mathrm{NO}_{\mathrm{x}}$ content decreases.

\section{CONCLUSION}

In general, the use of water injection leads to an increase in the effective power of the diesel engine, increase of its fuel efficiency and reduction of the content of harmful substances in the exhaust gases.

\section{References}

[1] It is calculated how many cars in Russia as of July 2016. Retrieved from: http://www.prav-net.ru/5669-ira/

[2] GOST R 41.96-2005 (UNECE Regulation No. 96) Uniform provisions concerning compression-ignition engines intended for installation on agricultural and forest tractors and off-road machinery for the emission of harmful substances by these engines. Retrieved from: http://docs.cntd.ru/document/1200042292

[3] GOST R 41.24-2003 (UN / ECE Regulation No. 96) Uniform provisions concerning the certification of engines with compression ignition with regard to smoke; II. Certification of vehicles with respect to the installation of compression-ignition engines certified by type of construction; III. Certification of vehicles with engines with compression ignition with respect to smoke; IV. Measurement of engine power. Retrieved from: http://docs.cntd.ru/document/1200034424

[4] GOST 18509-88 Diesel engines tractor and combine. Methods of bench tests. Retrieved from: http://docs.cntd.ru/document/1200010002

[5] GOST 20000-88 (ST SEV 1006-78) Diesel engines tractor and combine. General specifications. Retrieved from: http://docs.cntd.ru/document/1200009867

[6] Performance simulation and gas dynamics, WAVE, Product description, Ricardo Software, 2004, p. 94

[7] MTZ-80/82 tractors by adding water to the air supply system", Diss. kand. of tech. sciences (05.20.01), Chelyabinsk, 2009, p. 157.

[8] O. Bystrov, "Improving the economic and environmental performance of diesel by implementing a combined six-cycle", Diss. kand. of tech. sciences, Chelyabinsk, 2008.

[9] G. Medvedev, A. Melbert, A. Novoselov, "Improvement of emissions of diesel engines in composite materials containing Nickel", "Scientific problems of transport in Siberia and the Far East", 2013, No. 1, pp. 207. 210.

[10] M. Khasanova, "Universal indicators of reducing the toxicity of diese exhaust gases using the utilization system", LIV international scientific and technical conference "Achievement of science - agro-industrial production", Chelyabinsk, 2015, pp. 207-212.

[11] Yu. Maksimeyko, A. Melbert, G. Medvedev, "Reduction of harmful emissions in the period of pre-start-up of engines", Proceedings of the conference "Problems of environmental safety", November 27, Rubtsovsk, 2014.

[12] W. Willard, "Pulkrabek Engineering Fundamentals of the Internal Combustion Engine", Prentice Hall, Upper Saddle River, New Jersey, 2003, pp. 111-119. 